\title{
Hypovitaminosis D in recent onset rheumatoid arthritis is predictive of reduced response to treatment and increased disease activity: a 12 month follow-up study
}

Manuela Di Franco ${ }^{1}$, Ilaria Barchetta ${ }^{2}$, Cristina lannuccelli ${ }^{1}$, Maria Chiara Gerardi ${ }^{1}$, Silvia Frisenda ${ }^{1}$, Fulvia Ceccarelli ${ }^{1}$, Guido Valesini ${ }^{1}$ and Maria Gisella Cavallo ${ }^{2^{*}}$

\begin{abstract}
Background: Vitamin D displays immunomodulatory activities and has been proposed as a potential player in the pathogenesis of rheumatoid arthritis (RA). A negative association between serum $25(\mathrm{OH})$ vitamin $\mathrm{D}$ levels and RA activity was demonstrated but longitudinal studies investigating the role of vitamin D levels in predicting RA activity and response to treatment are lacking. Therefore, this study was designed to test the hypothesis of an association between serum $25(\mathrm{OH})$ vitamin D levels at RA diagnosis and disease activity evaluated by clinimetric, laboratory and ultrasound (US) parameters and to detect the prevalence of remission and response to treatment after 12 months follow-up.

Methods: This is a longitudinal, retrospective study on data obtained from thirty-seven patients with early RA treatment-naïve. Serum inflammatory markers, auto-antibodies and $25(\mathrm{OH})$ vitamin D levels were obtained at baseline. Hypovitaminosis D was diagnosed for $25(\mathrm{OH})$ vitamin D levels $<20 \mathrm{ng} / \mathrm{ml}$. Tender joint count (TJCs), swollen joint count (SJCs), Visual Analog Scales (VAS), Disease Activity Score (DAS) 28 score were assessed at baseline and 12 months after diagnosis. Joints synovitis and power-Doppler were evaluated at baseline and 12 months later.

Results: At baseline mean $25(\mathrm{OH})$ vitamin D levels were $24.4 \pm 11.9 \mathrm{ng} / \mathrm{ml} ; 35 \%$ of study subjects had hypovitaminosis D which strongly associated with higher RA activity and lower prevalence of remission and response to treatment (all $p$-values $<0.001$ ). The percentage of patients not presenting a reduction of the US synovitis score after 12 months from diagnosis was significantly higher among patients with hypovitaminosis D than in those with normal serum 25(OH) vitamin $\mathrm{D}$ at baseline.

Conclusions: In patients with early RA and basal hypovitaminosis D after 12 months follow-up reduction of disease activity and percentage of remission and response to treatment were significantly lower than those observed in patients with normal vitamin D levels. These results provide further support to the immunomodulatory action of vitamin $D$ in RA and suggest a role of basal vitamin $D$ status in the prediction of disease evolution. Vitamin $D$ measurement and possibly vitamin D supplementation should be considered an additional option in the management of early RA patients.
\end{abstract}

Keywords: Rheumatoid arthritis, Vitamin D, Disease activity, Musculoskeletal ultrasonography, Response to treatment

\footnotetext{
* Correspondence: gisella.cavallo@uniroma1.it

${ }^{2}$ Internal Medicine Unit-Department of Internal Medicine and Medical Specialties, Sapienza University of Rome, Viale del Policlinico 155, Rome 00161, Italy

Full list of author information is available at the end of the article
} 


\section{Background}

Rheumatoid arthritis (RA) is a chronic autoimmune disease characterized by joint involvement and systemic features, leading to a progressive disability and early death [1]. It affects approximately $1 \%$ of the population, with higher prevalence in women. Although its aetiology is still unknown, it has been theorized that in genetically susceptible individuals environmental factors trigger an autoimmune response resulting in synovial hypertrophy and chronic joint inflammation and destruction associated with potential extra-articular manifestations [2]. It has been demonstrated that the active form of vitamin $\mathrm{D}$, the 1,25-dihydroxyvitamin $\mathrm{D}\left(1,25(\mathrm{OH})_{2} \mathrm{D}\right)$, besides its role in calcium and bone homeostasis, acts as a modulator of immune cells such as macrophages, dendritic cells and activated T cells, expressing its specific vitamin D receptor (VDR) [3,4]. Furthermore, $1,25(\mathrm{OH})_{2} \mathrm{D}$ displays an anti-inflammatory role also acting on Th17 cells, contributing to the maintenance of the immunological homeostasis [5-7]. In murine models $1,25(\mathrm{OH})_{2} \mathrm{D}$ was able to prevent the onset and progression of arthritis and VDR deficient mice (VDR-/-) showed a more aggressive disease [8,9]. Some epidemiological studies showed a higher prevalence of vitamin D deficiency among patients affected by RA compared with healthy population [10-15], whereas other investigations did not confirm these findings $[16,17]$. Furthermore, a recent metaanalysis demonstrated that low vitamin D intake is associated with high risk of RA and that a negative association exists between serum vitamin D levels and RA activity [18]. Likewise, evidence about the relationship between hypovitaminosis D and early RA are contrasting [19-21].

Interestingly, an intervention trial conducted in a population of patients with early RA and disease-modifying antirheumatic drugs (DMARDs)-naïve showed that trimestral calcitriol supplementation along with triple DMARDs therapy resulted in significant higher pain relief compared with treatment with triple DMARDs plus calcium [14].

At the best of our knowledge, longitudinal studies investigating the role of vitamin D levels at RA diagnosis on the prediction of disease's activity, remission and response to treatment are missing. Therefore, aims of this study were to test the hypothesis of an association between serum 25 $(\mathrm{OH})$ vitamin D levels at the diagnosis of RA and: 1- the disease's activity evaluated by clinimetric, laboratory and ultrasound (US) parameters, 2- the prevalence of remission and response to treatment in a population of patients affected by early RA naïve for DMARDs treatment, after 12 months of follow-up.

\section{Methods}

\section{Study population}

This is a longitudinal observational retrospective study with a 12 months follow-up. Data from seventy-six consecutive patients referring to the Early Arthritis Clinic,
Rheumatology Unit, Sapienza University of Rome, for recently onset RA between 2010 and 2012 were initially obtained. Among them, we enrolled subjects which fulfilled the following inclusion criteria: age between 30 and 65 years, subjects meeting the American College of Rheumatology/European League Against Rheumatism (ACR/EULAR) criteria for RA diagnosis [22], mean disease duration $\leq 24$ weeks, BMI $16-25 \mathrm{~kg} / \mathrm{m}^{2}$, conscious acceptance of written informed consent. The exclusion criteria were: treatment with vitamin $\mathrm{D}$ and/or calcium supplementation or drugs affecting the bone and mineral metabolism, multivitamin supplementation, oral contraceptives, parathyroid hormone, L-tyroxine, diuretics, DMARDs, anti-epilepsies and steroids; intestinal malabsorption; diseases associated with hypercalcaemia (lymphoma, sarcoidosis, tuberculosis infection, primary hyperparathyroidism); acute/chronic kidney failure; acute/chronic hepatic failure; type 1 and type 2 diabetes mellitus; metabolic syndrome; history of drugs and/or alcohol abuse. Among the initial seventy-six patients, thirty-seven subjects were considered eligible for the study: fifteen patients were excluded for treatment with drugs affecting the bone and mineral metabolism, eight for multivitamin supplementation, one for oral contraceptives, three for treatment with steroids, one for intestinal malabsorption, two for chronic kidney failure, five for diabetes mellitus, three for metabolic syndrome and one refused to participate.

Study population underwent 12 months follow-up (mean \pm SD: $54 \pm 3$ weeks) during which they were treated with low doses of corticosteroids (Prednisone $<10 \mathrm{mg} /$ day) and methotrexate (7.5-15 mg/week) and attended to quarterly recall visits for clinical evaluation.

\section{Laboratory tests}

For each patient, we collected and analyzed data at baseline (disease onset) and after 12-months follow-up on medical history, physical examination and blood immuneinflammatory parameters, such as: erythrocyte sedimentation rate (ESR) (normal values: $\leq 15 \mathrm{~mm} / \mathrm{h}$ in men and $\leq 20 \mathrm{~mm} / \mathrm{h}$ in female), C-reactive protein (CRP) level (normal values: $<3 \mathrm{mg} / \mathrm{L}$ ), using standard laboratory methods and to detect IgM-Rhematoid Factor (RF) by nephelometric method ( $\mathrm{N}$ latex FR, Bering, $\mathrm{CV}<4 \%$ ) and anti-citrullinated protein antibodies (ACPA) by immune-enzymatic method (ImmunoCap, Phadia, <5\%). A titre of IgM-RF $>15 \mathrm{IU} / \mathrm{ml}$ was considered positive, the cut-off point for ACPA positivity was $>12 \mathrm{IU} / \mathrm{ml}$, according to the manufacturer's instructions.

In order to evaluate vitamin $\mathrm{D}$ status in our population at the diagnosis of RA, serum levels of $25(\mathrm{OH})$ vitamin $\mathrm{D}(\mathrm{ng} / \mathrm{ml})$, the most stable circulating form of this molecule were also measured [23,24]. In order to minimize the impact of seasonality on circulating vitamin D concentrations, all participants underwent fasting blood 
sampling for serum $25(\mathrm{OH})$ vitamin D measurement during autumn-winter period. Vitamin D was measured by immunochemiluminescent method (LIAISON, DiaSorin, $\mathrm{CV}<5 \%$ ) on sera frozen immediately after separation and stored at $-25^{\circ} \mathrm{C}$ for few days.

\section{Clinical assessment}

Clinimetric assessment, routinely used in clinical practice and Clinical Trials to evaluate disease activity and response to treatment, was performed by a rheumatologist experienced in clinimetric evaluation and blinded to laboratory data. At baseline and 12 months of follow up we collected data on: the number of tender and swollen joints on the basis of the 28-joint count and 44-joint count, Ritchie index (a graded assessment of 26 joint regions), visual analogue scale (VAS $0-100 \mathrm{~mm}$ ) for pain and patient's disease activity, examinator's global disease activity assessment (EGA), patient global health assessment $(\mathrm{GH})$ and 28-joints Disease Activity Score (DAS28) [25].

At 12 months follow-up, EULAR response was calculated from the DAS28 scores. Study population was divided in three EULAR response groups: no response, moderate response or good response. To be a good responder, a patient had to show an improvement of at least 1.2 units and achieve an absolute score of $<3.2$. Non-responders had to show an improvement of $<0.6$, or $>0.6$ and $\leq 1.2$, and have a final DAS28 score of $>5.1$. Moderate responses fell inbetween these criteria [26].

\section{Musculoskeletal ultrasonography}

US evaluation was performed both at baseline and after a 12-months follow-up. A systematic multiplanar greyscale and powerDoppler (pD) examination of 17 joints [wrist, metacarpophalangeal (MCP) joints, proximal interphalangeal (PIP) joints, knee and metatarsophalangeal (MTP) joints bilaterally] was performed according to standard EULAR guidelines, by MyLab70 XVision Gold (Esaote, Italy) machine equipped with a multifrequency linear probe $(6-18 \mathrm{MHz})$; powerDoppler PFR (peak frequency ratio) was $750 \mathrm{~Hz}$, Doppler frequency was 7.5 MHz. Synovial effusion (SE), synovial hypertrophy $(\mathrm{SH})$ and bone erosions were assessed according to the Outcome Measures in Rheumatoid Arthritis Clinical Trial (OMERACT) definitions [27]. US-detected elementary lesions ( $\mathrm{SE}, \mathrm{SH}$ and $\mathrm{pD}$ signal) were scored according to a semiquantitative scale based on the severity of the US modifications $(0=$ normal; $1=$ mild; $2=$ moder ate; 3 =severe). The total synovitis score was obtained from the sum of the all US modifications identified in all the joints. Bone erosions were assessed with a semiquantitative score as follows: grade $0=$ no erosion, grade $1=1$ erosion, grade $2=2$ erosions, grade $3 \geq 3$ erosions.

\section{Statistics}

SPSS version 17 statistical package was used to perform the analyses. Non-parametric Mann-Whitney test for mean comparison between two independent groups and Wilcoxon test for mean comparison between two related groups were used. The $X$-squared test was used to compare the rate of responders to treatment at 12 months follow-up (moderate + good response vs non response) among patients with and without basal hypovitaminosis D. Bivariate correlation analyses were performed by Spearman's coefficient calculation. Study population was divided in two subgroups according to vitamin $\mathrm{D}$ status considering serum $25(\mathrm{OH})$ vitamin $\mathrm{D}<20 \mathrm{ng} / \mathrm{ml}$ as a cut-off for insufficient vitamin D levels $[28,29]$. At the best of our knowledge, clinical remission and response to treatment by DAS28 after a 12 months follow-up in relation to vitamin D status at RA onset have never been studied before. Therefore, in order to confirm the statistical power of this study, we performed a post-hoc sample size calculation considering a prevalence of remission in the subgroup with normal vitamin D status of $68 \%$ and of $16 \%$ in patients with hypovitaminosis $\mathrm{D}$; thus, we obtained that eleven patients per subgroup were enough to reach the statistical significance with a power of $80 \%$ ( $\alpha$ error $=0.05$, $\beta$ error $=0.20$ ). For all the above, a $p$-value $<0.05$ was considered statistically significant. Study protocol was reviewed and approved by the Ethics Committee of Policlinico Umberto I, Sapienza University of Rome and conducted in conformance with the Helsinki Declaration. Written consent was obtained from all patients before the study.

\section{Results}

The study included 37 early RA patients. These were mostly female $(6 \mathrm{M} / 31 \mathrm{~F})$ with a mean (SD) age of $47 \pm$ 12 years and median disease duration (SD) of $24 \pm$ 13 weeks. Clinical, biochemical and US characteristics of study population at baseline and after 12 months from diagnosis are shown in Table 1.

\section{Baseline characteristics}

Study population had mean serum $25(\mathrm{OH})$ vitamin D concentrations of $24.4 \pm 11.9 \mathrm{ng} / \mathrm{ml}$; notably, $35 \%$ of our sample was affected by hypovitaminosis D at the time of RA diagnosis. Serum 25(OH) vitamin levels were not associated with basal DAS28. In order to characterize our patients according to vitamin D status, we stratified the study sample in two subgroups in relation to the vitamin D balance: patients affected by hypovitaminosis D $(25(\mathrm{OH})$ vitamin $\mathrm{D} \leq 20 \mathrm{ng} / \mathrm{ml}$ ) and with sufficient vitamin $\mathrm{D}$ levels (25 $(\mathrm{OH})$ vitamin $\mathrm{D}>20 \mathrm{ng} / \mathrm{ml})$.

Baseline clinimetric, biochemical and US characteristics did not differ significantly between the two subpopulations although there was a trend in increased prevalence 
Table 1 Clinimetric, laboratory and ultrasound characteristics of study population at baseline and after 12 months follow-up

\begin{tabular}{|c|c|c|c|}
\hline Patients $(\mathrm{N}=37)$ & Baseline & 12 months follow-up & P-value \\
\hline ESR $(\mathrm{mm} / \mathrm{h})$, mean $\pm \mathrm{SD}$ & $31 \pm 21$ & $13.9 \pm 11$ & $0.0001 \wedge$ \\
\hline $\mathrm{CRP}(\mathrm{g} / \mathrm{L})$, mean $\pm \mathrm{SD}$ & $13.6 \pm 16$ & $5.81 \pm 4.71$ & $0.003 \wedge$ \\
\hline RF positivity, number (\%) & $31(83)$ & $31(83)$ & - \\
\hline APCA positivity, number (\%) & $30(81)$ & $30(8)$ & - \\
\hline Morning stiffness (minutes), mean $\pm \mathrm{SD}$ & $62 \pm 48$ & $20.8 \pm 23$ & $0.0001 \wedge$ \\
\hline Ritchie index, mean $\pm S D$ & $10 \pm 8.2$ & $2.5 \pm 2.9$ & $0.00001 \wedge$ \\
\hline VAS pain $(\mathrm{mm})$, mean \pm SD & $63 \pm 24$ & $31.9 \pm 32$ & $0.002^{\wedge}$ \\
\hline VAS disease patient $(\mathrm{mm})$, mean \pm SD & $58 \pm 23$ & $31 \pm 27$ & $0.0001 \wedge$ \\
\hline $\mathrm{EGA}(\mathrm{mm})$, mean $\pm \mathrm{SD}$ & $54 \pm 20$ & $24.3 \pm 20$ & $0.0001 \wedge$ \\
\hline Number of tender joints (0-44), median (range) & $12(0-35)$ & $2(0-19)$ & $00001 \wedge$ \\
\hline Number of swollen joints (0-44), median (range) & $5(0-22)$ & $3(0-21)$ & $0.0001 \wedge$ \\
\hline Number of tender joints (0-28), median (range) & $8(0-24)$ & $4(0-30)$ & $0.0001 \wedge$ \\
\hline Number of swollen joints (0-28), median (range) & $5(0-20$ & $5(0-32)$ & $0.0001 \wedge$ \\
\hline DAS 28 score, mean \pm SD & $5.18 \pm 1$ & $2.77 \pm 1.14$ & $0.0001 \wedge$ \\
\hline Ultrasound Total Synovitis score, mean \pm SD & $25.7 \pm 21.7$ & $8.31 \pm 6.2$ & $0.0008 \wedge$ \\
\hline Ultrasound Total power Doppler score, mean \pm SD & $3.3 \pm 5.9$ & $0.65 \pm 1.22$ & $0.005^{\wedge}$ \\
\hline Ultrasound Total Erosion score, mean \pm SD & $1.34 \pm 2.7$ & $10.31 \pm 9.8$ & $n s^{\wedge}$ \\
\hline Patients $\geq 1$ erosion, number (\%) & $12(32 \%)$ & $18(48 \%)$ & $\mathrm{ns}^{*}$ \\
\hline X-Ray Erosion, +ve, number (\%)/\% & $6(16 \%)$ & - & \\
\hline
\end{tabular}

Results are shown as mean \pm SD, median(min-max) or number(percentage) of patients, as appropriated. $\wedge$ Wilcoxon test applied, ${ }^{*}$ chi-squared test applied. P-value $<0.05$ are considered significant. ESR, erythrocyte sedimentation rate; CRP, C-reactive protein; RF, Rheumatoid Factor; ACPA, anti-citrullinated protein antibodies; VAS, visual analogue scale; EGA, examinator's global disease activity assessment; DAS28, 28-joint disease activity score.

of ACPA and RF positivity and a higher US-pD score in patients affected by hypovitaminosis $\mathrm{D}$ compared with subjects with normal $25(\mathrm{OH})$ vitamin D levels. Furthermore, US synovitis joint score was significantly associated with DAS28 (Spearman's coefficient $=0.5$, $\mathrm{p}=0.003)$.

\section{2 months follow-up characteristics}

After 12 months from RA diagnosis in the overall population there was a significant reduction of disease's activity, as expressed by ESR, serum CRP levels, TJCs, SJCs and DAS28, and US synovitis and p-D score (all p-values < 0.001), as expected (Table 1).

Among the whole study population, individuals with hypovitaminosis $\mathrm{D}$ at baseline had significantly higher disease activity at the 12 months follow-up evaluated by clinimetric index, compared with patients with sufficient $25(\mathrm{OH})$ vitamin D levels. Furthermore, ESR, CRP and US inflammatory and US bone erosion scores were increased in presence of hypovitaminosis D although these differences did not reach the statistical significance. Clinimetric, laboratory and US characteristics of study population according to vitamin $\mathrm{D}$ status at baseline and 12 months follow-up are shown in Table 2.

\section{Response to RA treatment and clinical remission at 12 months from diagnosis}

After 12 months follow-up all participants were in treatment with low doses of corticosteroids (Prednisone $<10 \mathrm{mg} /$ day) and methotrexate (7.5-15 mg/week). Among our study population $91.7 \%$ patients were responders to RA treatment ( $2.7 \%$ good and $89 \%$ moderate responders) according to the EULAR response criteria. Disease remission (DAS28 < 2.6) was achieved by $48 \%$ of patients. The percentage of responders was significantly lower in the subgroup of patients with hypovitaminosis D compared to subjects with normal $25(\mathrm{OH})$ vitamin D levels at baseline $(25(\mathrm{OH})$ vitamin $\mathrm{D}<20 \mathrm{ng} / \mathrm{ml}: 75 \%$ responders $(0 \%$ good, $75 \%$ moderate response) vs $25(\mathrm{OH})$ vitamin $\mathrm{D}>20 \mathrm{ng} / \mathrm{ml}$ : $100 \%$ responders (4\% good, $96 \%$ moderate response, $\mathrm{p}<$ 0.001).

Similarly, the percentage of patients in remission was significantly reduced in hypovitaminosis D subgroup compared with the normal $25(\mathrm{OH})$ vitamin $\mathrm{D}$ one as showed by clinimetric index DAS28 ( $16 \%$ vs $68 \%, \mathrm{p}<0.001)$. The same results were obtained also using other clinimetric indexes such as DAS44, CDAI and SDAI (not shown) thus reinforcing the evidence for the association between hypovitaminosis $\mathrm{D}$ and disease activity/response to treatment. 
Table 2 Characteristics of study population at baseline and after 12 months follow-up according to vitamin D status at the time of RA diagnosis

\begin{tabular}{|c|c|c|c|c|c|c|}
\hline \multirow[t]{2}{*}{ Parameters } & \multicolumn{3}{|l|}{ Baseline } & \multicolumn{3}{|l|}{12 months follow up } \\
\hline & $\begin{array}{l}25(\mathrm{OH}) \mathrm{D}<20 \mathrm{ng} / \mathrm{ml} \\
(\mathrm{N}=13)\end{array}$ & $\begin{array}{l}25(\mathrm{OH}) \mathrm{D}>20 \mathrm{ng} / \mathrm{ml} \\
(\mathrm{N}=24)\end{array}$ & P-value & $\begin{array}{l}25(\mathrm{OH}) \mathrm{D}<20 \mathrm{ng} / \mathrm{ml} \\
(\mathrm{N}=13)\end{array}$ & $\begin{array}{l}25(\mathrm{OH}) \mathrm{D}>20 \mathrm{ng} / \mathrm{ml} \\
(\mathrm{N}=24)\end{array}$ & P-value \\
\hline Age, mean \pm SD & $51.3 \pm 13.1$ & $46.0 \pm 11.2$ & $\mathrm{~ns}^{\wedge}$ & - & - & - \\
\hline Sex, M/F & $2 / 11$ & $3 / 22$ & $n s^{*}$ & - & - & - \\
\hline $\mathrm{BMI}\left(\mathrm{Kg} / \mathrm{m}^{2}\right)$, mean $\pm \mathrm{SD}$ & $25.5 \pm 5.2$ & $25.5 \pm 4.2$ & $\mathrm{~ns}^{\wedge}$ & - & - & - \\
\hline Vitamin $D(n g / m l)$, mean $\pm S D$ & $12.4 \pm 3.4$ & $30.4 \pm 9.9$ & $0.0001 \wedge$ & - & - & - \\
\hline Disease Duration (weeks), mean \pm SD & $21.6 \pm 12.8$ & $23.8 \pm 18.1$ & $n s^{\wedge}$ & - & - & - \\
\hline Morning stiffness (minutes), mean \pm SD & $56.6 \pm 49.4$ & $83.6 \pm 102.2$ & $n s^{\wedge}$ & $38.3 \pm 27.2$ & $12.1 \pm 15.8$ & $0.002 \wedge$ \\
\hline $\mathrm{ESR}(\mathrm{mm} / \mathrm{h})$, mean $\pm \mathrm{SD}$ & $25.9 \pm 13.1$ & $35.5 \pm 25.4$ & ns^ & $15 \pm 10$ & $13.4 \pm 12.9$ & $\mathrm{~ns}^{\wedge}$ \\
\hline $\mathrm{CRP}(\mathrm{g} / \mathrm{L})$, mean $\pm \mathrm{SD}$ & $8.2 \pm 8.2$ & $16.4 \pm 19.3$ & ns^ & $5.1 \pm 4.2$ & $4.1 \pm 4.7$ & $\mathrm{~ns}^{\wedge}$ \\
\hline RF positivity, number (\%) & $11(85 \%)$ & $20(83 \%)$ & $\mathrm{ns} *$ & $9(69 \%)$ & $13(54 \%)$ & $0.002^{*}$ \\
\hline APCA positivity, number (\%) & $11(85 \%)$ & 19 (79\%) & $n s^{*}$ & $10(77 \%)$ & $18(75 \%)$ & $\mathrm{ns}^{*}$ \\
\hline Ritchie Index, mean \pm SD & $10.5 \pm 8.45$ & $9.71 \pm 8.32$ & $\mathrm{~ns}^{\wedge}$ & $4.25 \pm 3.52$ & $1.62 \pm 2.28$ & $0.004 \wedge$ \\
\hline VAS pain $(\mathrm{mm})$, mean \pm SD & $64.2 \pm 19.9$ & $60.8 \pm 27$ & $\mathrm{~ns}^{\wedge}$ & $61.4 \pm 31.2$ & $20.1 \pm 25.1$ & $0.001 \wedge$ \\
\hline VAS disease patient $(\mathrm{mm})$, mean \pm SD & $58 \pm 23.6$ & $57.8 \pm 24.4$ & $\mathrm{~ns}^{\wedge}$ & $48.7 \pm 27.3$ & $21.6 \pm 22.3$ & $0.004 \wedge$ \\
\hline $\mathrm{EGA}(\mathrm{mm})$, mean $\pm \mathrm{SD}$ & $52.7 \pm 26.2$ & $54.8 \pm 18.3$ & $\mathrm{~ns}^{\wedge}$ & $36 \pm 20.5$ & $17.6 \pm 18.5$ & $0.01 \wedge$ \\
\hline Global Health, mean \pm SD & $48.6 \pm 22.3$ & $63.9 \pm 17.3$ & $\mathrm{~ns}^{\wedge}$ & $35 \pm 16.2$ & $17.3 \pm 11.8$ & $0.03 \wedge$ \\
\hline $\begin{array}{l}\text { Number of tender joints (0-44), } \\
\text { median (range) }\end{array}$ & $11.5(2-35)$ & $11.5(0-33)$ & $n s^{\wedge}$ & $6(1-19)$ & $1(0-13)$ & $0.002^{\wedge}$ \\
\hline $\begin{array}{l}\text { Number of swollen joints (0-44), } \\
\text { median (range) }\end{array}$ & $5(1-22)$ & $5.5(0-13)$ & $n s^{\wedge}$ & $1.5(0-9)$ & $0(0-8)$ & $0.02 \wedge$ \\
\hline $\begin{array}{l}\text { Number of tender joints (0-28), } \\
\text { median (range) }\end{array}$ & $7(2-24)$ & $7.5(0-23)$ & $n s^{\wedge}$ & $3.5(1-11)$ & $0(0-4)$ & $0.001 \wedge$ \\
\hline $\begin{array}{l}\text { Number of swollen joints (0-28), } \\
\text { median (range) }\end{array}$ & $3.5(1-20)$ & $5(0-13)$ & $n s^{\wedge}$ & $1.5(0-8)$ & $0(0-8)$ & $0.01 \wedge$ \\
\hline DAS 28 score, mean \pm SD & $5.1 \pm 0.7$ & $5.2 \pm 1.2$ & $n s^{\wedge}$ & $3.6 \pm 1.03$ & $2.3 \pm 0.9$ & $0.001 \wedge$ \\
\hline Remission (DAS28 < 2.6), number (\%) & - & - & - & $2(16)$ & $16(68)$ & 0.001 \\
\hline $\begin{array}{l}\text { Low disease activity (DAS28 2.6-3.2), } \\
\text { number (\%) }\end{array}$ & $0(0)$ & $1(4.2)$ & & $2(15)$ & $4(16)$ & \\
\hline $\begin{array}{l}\text { Moderate disease activity } \\
\text { (DAS } 28 \text { 3.2-5.1), number (\%) }\end{array}$ & $10(77)$ & $11(45.8)$ & & $8(62)$ & $3(12)$ & \\
\hline $\begin{array}{l}\text { High disease activity (DAS28 > 5.6), } \\
\text { number }(\%)\end{array}$ & $4(23)$ & $12(50)$ & & $1(8)$ & $1(4)$ & \\
\hline Good responders, number (\%) & - & - & - & $0(0)$ & $1(4)$ & \\
\hline Moderate responders, number (\%) & - & - & - & $10(75)$ & $23(96)$ & \\
\hline No responders, number (\%) & - & - & - & $3(25)$ & $0(0)$ & \\
\hline $\begin{array}{l}\text { Ultrasound Total Synovitis score, } \\
\text { mean } \pm \text { SD }\end{array}$ & $26.5 \pm 31.3$ & $25.4 \pm 17.4$ & $n s^{\wedge}$ & $14.3 \pm 15.6$ & $8.1 \pm 6.2$ & $\mathrm{~ns} \wedge$ \\
\hline $\begin{array}{l}\text { Ultrasound Total power Doppler score, } \\
\text { mean } \pm \text { SD }\end{array}$ & $4.6 \pm 8.9$ & $2.7 \pm 4.2$ & $n s^{\wedge}$ & $0.83 \pm 1.32$ & $0.57 \pm 1.26$ & $\mathrm{~ns}^{\wedge}$ \\
\hline $\begin{array}{l}\text { Ultrasound Total Erosion score, } \\
\text { mean } \pm \text { SD }\end{array}$ & $1.2 \pm 2.3$ & $1.4 \pm 3$ & $n s^{\wedge}$ & $11.8 \pm 6.4$ & $9.6 \pm 11.2$ & $\mathrm{~ns} \wedge$ \\
\hline
\end{tabular}

Results are shown as mean \pm SD or number (percentage) of patients, as appropriated. $\wedge$ Mann-Whitney test applied, ${ }^{*}$ chi-squared test applied. P-value $<0.05$ are considered significant. ESR, erythrocyte sedimentation rate; CRP, C-reactive protein; RF, Rheumatoid Factor; ACPA, anti-citrullinated protein antibodies; VAS, visual analogue scale; EGA, examinator's global disease activity assessment; DAS28, 28-joint disease activity score.

The bivariate correlation analyses showed that the response to RA treatment and the clinical remission after 12-month from RA diagnosis were associated with baseline vitamin D status (Spearman's coefficient 0.45, $\mathrm{p}=0.006$; Spearman's coefficient $0.55, \mathrm{p}<0.001$, respectively) and did not correlate with age, gender, BMI, CRP, ESV, DAS28, 
ACPA and RF positivity at the time of RA diagnosis. Moreover, the multivariate logistic analysis demonstrated that baseline vitamin D status independently predicted the response to RA treatment after adjusting for age, gender and all possible confounders $(\mathrm{p}<0.006$, see also Additional file 1: Table S1). Notably, in our study population, baseline hypovitaminosis $\mathrm{D}$ was associated with an over 3-fold increase (OR: 3.5 ; 95\% C.I.: 1.3-9.5, $\chi^{2}$ test applied) in the risk of no response to RA treatment after 12 months follow-up.

The existence of a worse response to treatment in patients with hypovitaminosis $\mathrm{D}$ compared to those with normal 25(OH) vitamin D levels at RA onset was also demonstrated by US. Although individual US scores underwent changes that were not significantly different between the two groups, when calculating the difference between US total synovitis scores at baseline and 12month follow-up, a significant difference was observed between score variation in patients with hypovitaminosis $\mathrm{D}$ and the one in patients with normal $25(\mathrm{OH})$ vitamin D (Variation: $-7.1 \pm 15.3$ vs $-20.4 \pm 12.9$, respectively; $\mathrm{p}=0.01)$.

\section{Discussion}

In this study we demonstrated that the occurrence of hypovitaminosis D in early RA is predictive of a reduced response to treatment and higher disease activity as evaluated after 12 months follow-up. Low vitamin D levels were found in $35 \%$ of study population and vitamin D levels were not associated with basal RA activity. So far, conflicting evidence exists regarding the association between vitamin D deficiency and RA susceptibility and prognosis. Although an overall high prevalence of vitamin D deficiency in RA has been largely described, some studies found comparable serum $25(\mathrm{OH})$ vitamin D concentrations between patients with RA and healthy controls $[16,17]$. Gheita TA et al. recently found reduced 25(OH) vitamin D levels in RA patients compared with controls and that, among RA patients, vitamin D was significantly lower in subjects with fibromyalgia syndrome in addition to RA [15]. Other studies evaluated prospectively the risk of RA in relation to vitamin $\mathrm{D}$ intake, but again the results are conflicting [18,30,31].

So far, evidence of a relationship between vitamin D serum levels and disease activity in early RA patients is limited to a report on a negative association $[21,32]$ between serum vitamin $\mathrm{D}$ at baseline and HAQ score after 12 months follow-up, but neither RA activity nor response to treatment were investigated. Cross-sectional studies on the association between baseline $25(\mathrm{OH})$ vitamin D levels and disease's activity in early RA patients did not obtain univocal results [19-21].

In our study, as expected, we observed an overall significant reduction of RA activity, evaluated by clinimetric, laboratory and US parameters, after 12 months of treatment. In fact, the outcome of the disease has improved considerably in recent years with the availability of effective therapies and the recognition that early intensive treatment strategies result in better outcomes. Interestingly, at the end of follow-up we found that patients with hypovitaminosis D exhibited significantly higher disease activity and reduced percentage of remission and lower response to treatment compared with those with sufficient $25(\mathrm{OH})$ vitamin D levels at baseline, suggesting a role of vitamin $\mathrm{D}$ in disease progression and prognosis. Over the past decade the immunomodulatory role of vitamin D has become more defined. Experimental data show that vitamin D metabolites play a modulatory role on $\mathrm{T}$ cell proliferation and dendritic cell function via VDRs expression on these cells [33]. Notably, the expression of VDRs was also demonstrated on activated lymphocytes, synoviocytes, macrophages, and chondrocytes in the course of RA [33]. In murine models of collagen-induced arthritis, vitamin D supplementation prevents both the onset and progression of arthritis [8]. Further support for a role of VDR/vitamin D system in the pathogenesis of RA is also provided by epidemiological studies showing the existence of an association between VDR Fok1polymorphism and RA susceptibility $[34,35]$.

One limitation of the present study is the small number of patients; another limit is the short duration follow-up, as 12 months may not be enough to ascertain whether vitamin D status at baseline has long term effects on RA activity, particularly referring to structural damage. Moreover, as no previous data are available on clinical remission/response to treatment after a 12 month followup in relation to vitamin D status at RA onset, we just performed a post-hoc sample size calculation, confirming the statistical power of our findings.

Our study however, has several strengths: it is the first longitudinal study investigating the role of vitamin D status in predicting RA activity and response to treatment in early and DMARDs-naïve RA and evaluates for the first time the prognostic value of vitamin D status on US parameters in RA, such as synovitis, $\mathrm{p}-\mathrm{D}$ and bone erosion US scores.

\section{Conclusions}

In conclusion, our study demonstrates that hypovitaminosis D at RA onset is predictive of a reduced response to treatment in early RA after 12 months of follow-up. These results provide further support to the immunomodulatory action of vitamin D in inflammatory arthritis and suggest a potential prognostic role of vitamin D status at diagnosis in RA evolution. Serum vitamin D measurement and possibly vitamin D supplementation should be considered an additional option in the management of early RA patients. 


\section{Additional file}

Additional file 1: Table S1. Multivariate logistic analysis

\section{Abbreviations}

1,25(OH)2D: 1,25-dihydroxyvitamin D; ACPA: Anti-citrullinated protein antibodies; CRP: C-reactive protein; DAS28: 28-joint disease activity score; DMARDs: Disease-modifying anti-rheumatic drugs; EGA: Examinator's global disease activity assessment; ESR: Erythrocyte sedimentation rate; PFR: Peak frequency ratio; RA: Rheumatoid arthritis; RF: Rheumatoid Factor; SE: Synovial effusion; SH: Synovial hypertrophy; US: Ultrasound; VAS: Visual analogue scale; VDR: Vitamin D receptor.

\section{Competing interests}

The authors declare that they have no competing interests.

\section{Authors' contributions}

MDF conceived the study, participated in its design and coordination, made contributions to study implementation, and was involved in revising the manuscript critically for important intellectual content; IB participated in the design of the study, helped to draft the manuscript and performed the statistical analyses; Cl participated in the design of the study, had full access to all the data in the study and takes responsibility for its integrity and the accuracy of the data analysis; MCG participated in the acquisition of data, carried out clinical evaluation and made contributions to drafting the manuscript; SF carried out laboratory tests and made contributions to data acquisition and analysis; FC performed ultrasound evaluation and participated in data analysis; GV participated in the design of the study and have been involved in revising it critically for important intellectual content, MGC conceived the study, participated in its design and coordination and have given final approval of the version to be published. All authors read and approved the final manuscript.

\section{Acknowledgements}

This study was supported by a grant from Sapienza University of Rome.

\section{Author details}

${ }^{1}$ Rheumatology Unit-Department of Internal Medicine and Medical Specialties, Sapienza University of Rome, Viale del Policlinico 155, Rome 00161, Italy. ${ }^{2}$ Internal Medicine Unit-Department of Internal Medicine and Medical Specialties, Sapienza University of Rome, Viale del Policlinico 155, Rome 00161, Italy.

\section{Received: 1 September 2014 Accepted: 19 February 2015} Published online: 15 March 2015

\section{References}

1. Firestein GS. Evolving concepts of rheumatoid arthritis. Nature. 2003;15(423):356-61.

2. Mclnnes IB, Schett $G$. The pathogenesis of rheumatoid arthritis. N Engl J Med. 2011;365(23):2205-19

3. Boonstra A, Barrat FJ, Crain C, Heath VL, Savelkoul HF, O'Garra A. 1alpha, 25 Dihydroxyvitamin $\mathrm{d} 3$ has a direct effect on naive CD4(+) T cells to enhance the development of Th2 cells. J Immunol. 2001;167:4974-80.

4. Imazeki I, Matsuzaki J, Tsuji K, Nishimura T. Immunomodulating effect of vitaminD3 derivatives on type-1 cellular immunity. Biomed Res. 2006;27:1-9.

5. Daniel C, Sartory NA, Zahn N, Radeke HH, Stein JM. Immune modulatory treatment of trinitrobenzene sulfonic acid colitis with calcitriol is associated with a change of a T helper (Th) 1/Th17 to a Th2 and regulatory $T$ cell profile. J Pharmacol Exp Ther. 2008;324:23-33.

6. Tang J, Zhou R, Luger D, Zhu W, Silver PB, Grajewski RS, et al. Calcitriol suppresses antiretinal autoimmunity through inhibitory effects on the Th17 effector response. J Immunol. 2009;182(8):4624-32.

7. Chang SH, Chung Y, Dong C. Vitamin D suppresses Th17 cytokine production by inducing C/EBP homologous pro- tein (CHOP) expression. J Biol Chem. 2010;285(50):38751-5.

8. Cantorna MT, Hayes CE, DeLuca HF. 1,25-Dihydroxycholecalciferol inhibits the progression of arthritis in murine models of human arthritis. J Nutr. 1998;128(1):68-72.
9. Zwerina K, Baum W, Axmann R, Heiland GR, Distler JH, Smolen J, et al. Vitamin D receptor regulates TNF-mediated arthritis. Ann Rheum Dis. 2011;70(6):1122-9.

10. Broder AR, Tobin JN, Putterman C. Disease-specific definitions of Vitamin D deficiency need to be established in autoimmune and non-immune chronic diseases: a retrospective comparison of three chronic diseases. Arthritis Res Ther. 2010;12(5):R191.

11. Furuya T, Hosoi T, Tanaka E, Nakajima A, Taniguchi A, Momohara S, et al. Prevalence of and factors associated with vitamin D deficiency in 4,793 Japanese patients with rheumatoid arthritis. Clin Rheumatol. 2013;32(7):1081-7.

12. Haque UJ, Bartlett SJ. Relationships among vitamin D, disease activity, pain and disability in rheumatoid arthritis. Clin Exp Rheumatol. 2010;28(5):745-7.

13. Kerr GS, Sabahi I, Rchards JS, Caplan L, Cannon GW, Reimold A, et al. Prevalence of vitamin $D$ deficiency in rheumatoid arthritis and associations with disease severity and activity. J Rheumatol. 2011;38(1):53-9.

14. Gopinath K, Danda D. Supplementation of 1,25 dihydroxy vitamin D3 in patients with treatment naïve early rheumatoid arthritis: a randomized controlled trial. Int J Rheum Dis. 2011;14:332-9.

15. Gheita TA, Sayed S, Gheita HA, et al.: Vitamin D status in rheumatoid arthritis patients: relation to clinical manifestations, disease activity, quality of life and fibromyalgia syndrome. Int J Rheum Dis 2014 Oct 7. Epub ahead of print.

16. Cutolo M, Otsa K, Laas K, Yprus M, Lehtme R, Secchi ME, et al. Circannual vitamin $D$ serum levels and disease activity in rheumatoid arthritis: Northern versus Southern Europe. Clin Exp Rheumatol. 2006;24(6):702-4.

17. Turhanoğlu AD, Güler H, Yönden Z, Aslan F, Mansuroglu A, Ozer C. The relationship between vitamin $D$ and disease activity and functional health status in rheumatoid arthritis. Rheumatol Int. 2011;31(7):911-4.

18. Song GG, Bae SC, Lee YH. Association between vitamin D intake and the risk of rheumatoid arthritis: a meta-analysis. Clin Rheumatol. 2012;31(12):1733-9.

19. Zakeri Z, Sandoughi M, Mashhadi MA, Raeesi V, Shahbakhsh S: Serum vitamin $\mathrm{D}$ level and disease activity in patients with recent onset rheumatoid arthritis. Int J Rheum Dis 2013 Oct 18; doi:10.1111/1756185X.12181. [Epub ahead of print].

20. Craig SM, Yu F, Curtis JR, Alarcón GS, Conn DL, Jonas B, et al. Vitamin D status and its associations with disease activity and severity in African Americans with recent-onset rheumatoid arthritis. J Rheumatol. 2010;37(2):275-81.

21. Patel S, Farragher T, Berry J, Bunn D, Silman A, Symmons D. Association between serum vitamin $D$ metabolite levels and disease activity in patients with early inflammatory polyarthritis. Arthritis Rheum. 2007;56(7):2143-9.

22. Aletaha D, Neogi T, Silman AJ, Funovits J, Felson DT, Bingham CO, et al. Rheumatoid arthritis classification criteria: an American College of Rheumatology/European League against Rheumatism collaborative initiative. Arthritis Rheum. 2010;62:2569-81.

23. Holick MF. Vitamin D deficiency. N Engl J Med. 2007;357:266-281.15.

24. DeLuca HF. Overview of general physiologic features and functions of vitamin D. Am J Clin Nutr. 2004;80:1689S-96.

25. Prevoo ML, Hof MA v 't, Kuper HH, van Leeuwen MA, van de Putte LB, van Riel PL. Modified disease activity scores that include twenty-eight-joint counts: development and validation in a prospective longitudinal study of patients with rheumatoid arthritis. Arthritis Rheum. 1995;38:44-8.

26. VanGestel AM, Haagsma CJ, VanRiel PL. Validation of rheumatoid arthritis improvement criteria that include simplified joint counts. Arthritis Rheum. 1998;41(10):1845-50.

27. Wakefield RJ, Balint PV, Szkudlarek M, Filippucci E, Backhaus M, D'Agostino MA, et al. Musculoskeletal ultrasound including definitions for ultrasonographic pathology. J Rheumatol. 2005;32(12):2485-7.

28. Dawson-Hughes B, Heaney RP, Holick MF, Lips P, Meunier PJ, Vieth R. Estimates of Optimal Vitamin D Status. Osteoporos Int. 2005;16:713-6.

29. Dawson-Hughes B, Mithal A, Bonjour JP, Boonen S, Burckhardt P, Fuleihan GE, et al. IOF position statement: vitamin D recommendations for older adults. Osteoporos Int. 2010;21:1151-4.

30. Merlino LA, Curtis J, Mikuls TR, Cerhan JR, Criswell LA, Saag KG, et al. Vitamin $\mathrm{D}$ intake is inversely associated with rheumatoid arthritis: results from the lowa Women's Health Study. Arthritis Rheum. 2004;50(1):72-7.

31. Costenbader KH, Feskanich D, Holmes M, Karlson EW, Benito-Garcia E. Vitamin D intake and risks of systemic lupus erythematosus and rheumatoid arthritis in women. Ann Rheum Dis. 2008;67(4):530-535.16. 
32. Arnson $Y$, Amital $H$, Shoenfeld $Y$. Vitamin $D$ and autoimmunity: new aetiological and therapeutic considerations. Ann Rheum Dis. 2007;66:1137-42.

33. Tetlow L, Smith SJ, Mawer EB, Woolley DE. Vitamin D receptors in the rheumatoid lesion: expression by chondrocytes, macrophages, and synoviocytes. Ann Rheum Dis. 1999;58:118-21.

34. Lee Y, Bae S, Choi S, Ji J, Song G. Associations between vitamin D receptor polymorphisms and susceptibility to rheumatoid arthritis and systemic lupus erythematosus: a meta-analysis. Mol Biol Rep. 2011;38(6):3643-51.

35. Hitchon C, Sun Y, Robinson D, Peschken C, Bernstein C, Siminovitch $K$, et al. Vitamin $D$ receptor polymorphism rs2228570(FOK1) is associated with $R A$ in north American natives. J Rheumatol. 2012;39(9):1792-7.

\section{Submit your next manuscript to BioMed Central and take full advantage of:}

- Convenient online submission

- Thorough peer review

- No space constraints or color figure charges

- Immediate publication on acceptance

- Inclusion in PubMed, CAS, Scopus and Google Scholar

- Research which is freely available for redistribution 